\title{
WORK-INTEGRATED LEARNING FOR MASTER STUDENTS IN PRODUCT DEVELOPMENT
}

\author{
Pieter GHYSELS, Bianca ROSEAUX and Alexis JACOBY \\ University of Antwerp, Belgium
}

\begin{abstract}
Both graduate and undergraduate students in design and product development acquire very specific domain related competences throughout their study programme. These educational targets, compiled in 12 domain-specific core competences a student in product development should acquire, represent the foundation on which the programme curriculum is built. Every single part of the curriculum contributes to this goal. However, to comply with the high standards industry asks, an important set of soft skills is required. These soft skills relate very much to the real-life context of the innovation-oriented firm and are difficult to simulate in an educational context. Hence, the opportunity to outsource a part of the education needs to the working environment itself. This kind of work-integrated learning, in Belgium, is well established in the context of secondary and professional bachelor programmes but hardly in the context of academic master programmes. This paper describes a pilot project at the department of product development of the faculty of design sciences at the University of Antwerp, in which nine students accomplish their master thesis in close collaboration with an industrial partner and in which a specific focus was set on acquiring additional but not domain-specific skills. Defining additional skills and monitoring the evolution through self-assessment and self-reflection are the key enablers in this project. Throughout this project, students and industrial partners have participated in defining the approach, the competences and the way to evaluate the project.
\end{abstract}

Keywords: Work-integrated learning, soft skills, product development

\section{INTRODUCTION}

The product development programme at the University of Antwerp is a five-year programme that focuses on product design and development. Product design is to be understood in a very broad sense. It is about hardware products, about product-service systems and about systemic design. The three bachelor years concentrate on the design skills for well-defined design challenges, the two master years concentrate on both defining new and innovative products and services and managing the innovation process that should lead to innovation and new designs. The backbone of the product development programme is the design methodology that guides the design processes in a multi-disciplinary way. The programme builds on learning lines in economics, technology \& exact sciences, and human science. These varying disciplines are integrated in the learning line of design.

Throughout the entire programme diverse projects are conducted in collaboration with industry to provide a realistic setting for the projects and prepare students for the real-life context of industry.

In the $4^{\text {th }}$ year, the first master year, students participate in a 10-week internship in design consultancies or other firms in the context of design and development. The internship proposals are screened to guarantee an innovative context and a senior designer as a supervisor.

A project was granted by the European Social Funding Programme (ESF) for investigating how workintegrated learning could add value in an academic context. Specifically, as a pilot, in the context of the master programme in product development. The entire project has 3 main objectives:

1. Competence Development: By means of co-creation sessions with students and supervisors, the competences for work-integrated learning are defined, as well as the evaluation process.

2. Curriculum development: Rethinking the master's curriculum in Product Development to propose an elective parallel course programme that integrates work-integrated learning for a total of 39 credits.

3. Installation of a learning network over the entire university to share learnings and insights related to work-integrated learning on an academic level. 
The entire project runs for 18 months and includes the one-year pilot project in the Product Development programme. The pilot-case is to provide specific learnings for Product Development. It should also lead to a script for translating these learning to other academic master's programmes in the University of Antwerp.

\section{PILOT PROJECT}

In the final year of the product development programme, students can choose for the regular master thesis project, or they can apply for a master thesis internship in the context of a firm. In the regular master thesis, students have to define individually a new and innovative product or service (or a combination of both) and develop a concept for that innovative idea in order to find solutions for all criticalities that might prevent the idea from reaching the market. Students applying for a project in the context of a firm, define an innovative project in collaboration with the firm's staff. The project must meet both the demands of the university regarding learning outcomes and of the company regarding finding a match with the expertise present. During the entire year, the students work in close collaboration with the firm. The students are supposed to work at least two or three days a week in the firm. They have a supervisor within the company as well as an academic supervisor at the university. They have a weekly meeting with the academic supervisor.

In preparation of the master thesis, all 55 students were invited to an information meeting for a presentation of the pilot project. Twelve students attended the meeting and nine of them choose to participate in the pilot. Several reasons were mentioned for this choice. In a specific case, 4 students applied for the pilot because they were interested in the project. The other students mainly participated because they had good prior experiences with internships, or because they were convinced that an internship would improve their motivation for the hard work ahead.

A project board was installed with 10 external specialists in work-integrated learning before the start of the pilot. They all have similar projects running in their specific context (other universities, university colleges, public organizations) or are specialized in specific aspects of work-integrated learning (education development, soft skills). The project board's task is to define the research questions throughout the process, to assess the learnings and to provide input as from their specific perspective.

\subsection{Matchmaking}

For four students, the project and the company were known by the start of the project. For five other students the project and the company had to be found. For every student, a meeting was planned with an academic supervisor to define which aspirations students had regarding the company and the project. Based on these aspiration, different companies were suggested to the students. The students took the initiative to make appointments with the firms to discuss their aspirations and possible projects. Together with the external firms, the students prepared project proposals which they reported back to their academic supervisors. In two of the cases, this provided an approved project start. In three other cases, the project proposals could not meet the requirements for a master thesis project. To shortcut the process, the academic supervisor, the students and the external supervisors held a face-to-face meeting to discuss the project outlines until it would meet the requirements, expertise or interest for every party.

The external supervisors all agreed to participate actively in the pilot project by participating in cocreation sessions and focus group sessions to define and assess the pilot.

\subsection{Competence development}

During the pilot project, all stakeholders (students, academic supervisors and external supervisors) contributed to the deliverables by participating in co-creative workshops or focus group sessions in order to define which competences could be developed in a work-integrated learning environment and more importantly, how this competence development could be achieved.

\subsubsection{Soft skills development}

Within the pilot project, a first major focus was put on work-related soft skills that are hard to teach in the context of the university. A first focus group session was organized with the students and the external supervisors to detect whether a focus on soft skills is interesting and feasible for both students and supervisors. During the session was focused on the most important soft skills students in product development must deal with during their internship at a company. Following questions were addressed in the focus group setting: 
- What are the main contextual differences between the university and the industry?

- What will be the contextual differences in industry in 2020 compared to 2030? Which trends emerge?

- Which soft skills are poorly addressed during the bachelor and master's programme in product development? Or which soft skills should be addressed more thoroughly.

- Which soft skills can only be acquired during internship?

Starting from the larger picture, the external supervisors emphasized the importance of soft skills and the ability of life-long learning. The design discipline, but also technology and the socio-economic context change in a very fast pace. Having the right knowledge is less important than having the ability to acquire new knowledge. Apart from the discipline-related skills and mindsets, both the supervisors and the students agreed on the importance of following soft skills during the internship:

- Communication skills: a focus on informal communication with project team members, formal external communication with clients and suppliers, the ability to adapt the communication style to the different parties, non-violent communication in order to deliver clear messages in a diplomatic way, both positive and negative messages.

- Interdisciplinary collaboration with project team members from a different discipline,

- Dealing with criticism and providing positive critique to others.

- Self-reflection, the ability to assess the individual situation and to define a learning path for improvement.

- Project ownership, the ability to take the responsibility in a project and to take decisions. Additionally, the ability to assess the difference between key problems and non-critical partial problems.

- $\quad$ Flexibility, the ability for easy adaptation to changing project conditions.

- Time management, the ability to work on design projects within a clear time frame, adapting the process and the outcome to the time available.

- Intercultural collaboration

Regarding developing the soft skills, the focus group agreed that specific settings can be created to force the students to address the skills and learn while doing so. Interdisciplinary collaborations can be easily installed, for instance, to provide the necessary conditions to learn from the situation. To progress in specific soft skills, however, it seems necessary to define specific actions in collaboration with the supervisor that could contribute to the learning process. Weekly or two-weekly follow-up meetings are perceived necessary to address the learning process, evaluate prior steps and to define a new strategy for future learning.

\subsubsection{Self-reflection}

It is important that the students in these setting are being followed very well. Evaluation is a critical issue. And it is essential that students obtain feedback during the process so they can learn and adjust but it is also essential that students reflect on their process. The objective of self-reflection is to reach awareness to improve the learning process. Structured self-reflection helps students to connect practical experiences with academic learning outcomes addressed in the academic context. Self-reflection also yields, apart from academic competences, personal and social competences. However, self-reflection also requires tools and guidance before, during and after the practical working experience. Specific models such as the experimental learning cycle from Kolb (1984), or the Clayton Deal model (2009) provide potential frameworks for the self-reflection tool.

The work-integrated learning process includes, apart from the master thesis project, a 3-credit course on portfolio development which provides the necessary setting for organizing a self-reflection process.

Different self-reflection tools were assessed for the project, but they could not provide a dedicated answer for the need of this pilot. The tools mainly focused on generic reflection cycles.

In order to provide the right instrument for self-reflection a dedicated tool was developed that could help both the student and the external supervisor to define together the competences (soft skills) to acquire and to define the actual approach for getting there.

In a second workshop with 7 students, 4 external supervisors and 3 academic supervisors, the preliminary version of the tool was assessed. The workshop was organized while students were working in the company for some months. They were already familiar with their supervisors, the company's culture and the expectations regarding the master thesis project. 
The students were asked to define the soft skills categories (out of a list of 7) they wanted to focus on. They were provided with an elaborated list of about 15 criteria per category by which they could assess their actual level of competence for that soft skill, for instance communication or organization. The assessment led to the selection of very specific needs regarding specific soft skills, for instance the ability to take the lead in a project meeting.

In a second phase during the workshop, the students cooperated with their external supervisor to define which specific actions they could define to meet the desired outcome level regarding these skills. The tool provided some supporting questions for the action definition. By defining the specific role the company could play in order to achieve the learning outcomes, by defining the definition of success for a specific soft skill and by investigating which examples of actions could be detected within the context of the company.

All duos successfully completed the tool and reached the definition of concrete action points to address the needs for the soft skills the students described as being important to him or her.

During feedback, supervisors and students agreed that the toolkit provided a structured way to define concrete targets to work on. It also provided a working plan that could easily be followed over the months of cooperation and could provide a structure for feedback and evaluation.

Some remarks were made as well. It would be difficult to define these action points as from the very beginning of the project when student and supervisor are not yet acquainted with each other. The supervisors also remarked that the soft skill evaluation and feedback cannot be separated from the domain specific skills to be assessed during the project. They asked for an integration of the project evaluation tool with the tool to define and assess specific actions for soft skill development.

At the end of the workshop was also assessed in which way the external supervisors are willing to contribute to the student's learning process, not only from the project perspective but also from the soft skills perspective. For all external supervisors, the process of assessing soft skills in an internship situation is rather new. They are familiar with internship collaboration, but they admit, that, till now, their main concern was related to the project outcome itself. Although the workload for supervising would raise for this kind of process, they also understand how this could provide value for the student and they are willing to participate due to the lightweight instrument that is provided. Nevertheless, from their perspective it is mandatory to be very explicit about the expectation towards supervisors as from the beginning of a project.

\subsection{Curriculum development}

Curriculum development is not the critical aspect of the project. The programme of Product development has defined a work-integrated learning alternative for three courses: (i) The research and product definition course of 12 credits, which provides the foundation for the master thesis project, (ii) the actual master thesis project for 24 credits and the (iii) portfolio course for 3 credits. Portfolio works in two directions. It is a reflection course looking backwards to the entire product development programme and the master thesis and it looks forward to the finalization of the studies and prepares for the real upcoming working environment.

The work-integrated learning programme, at first, will not be a mandatory programme. Although many students could benefit from this setting, as for now, there are no arguments for deploying it for every student. Furthermore, the workload is supposed to be too heavy for the teaching staff.

\subsection{Learning network}

Along the pilot project, a learning network was set up with educational staff members from other faculties in and outside the university and with educational experts in order to share learnings and to support the installation of work-integrated learning in other faculties. The learning network is still in the preliminary phase. One meeting was organized to inform the network on the status of the pilot project. Other network meetings will follow to address specific topics:

- How can quality of work-integrated learning be guaranteed?

- What additional support is needed for supervisors?

- Which good practices can be shared? 


\section{LEARNINGS}

The pilot project is still running and entering the final phase. A first integrated version of the evaluation tool, comprising both domain specific skill and soft skill evaluation, is designed based on the results and remarks of the workshop with students and supervisors. The tool is developed as an online pdf file that can be filled in by both the supervisor and the student and is accessible by the academic promotor as well. It is a lean tool, proposing an easy procedure throughout the year, defining at first the initial status of the student, providing guidance for mid-term and final self-reflection for the student and evaluation for the supervisor over the period of the 10-month project.

The integrated tool is being tested with students and supervisors. However, some important remarks can already be made regarding the work-integrated learning process in relation to the matchmaking process, the support of the students in the work-integrated learning setting and the tool.

\subsection{Matchmaking}

The matchmaking process that was installed in the pilot project generates too much workload for the staff members. It was clear that the process of defining a project needed some extensive interventions from the staff to meet the master thesis requirements. The projects proposed did generally fit very well the specific context of the firm but failed to provide the necessary conditions for the students to meet all evaluation criteria at the end of the project. Criteria include the definition of a new, innovative idea for a product or service, the definition of all specifications and design criteria, the proposition of design solutions both on a system as on a concept level. This very large set of criteria asks for projects that start at the very front end of innovation and reach out until the design concept phase. Many projects proposed from industry could only provide for some of the necessary criteria.

The reflection was made that a good description of the criteria, combined with good examples could overcome this specific problem. However, practice showed us that mutual consultation is often needed. This is probably a specific problem for a design faculty where the learning competences are defined very extensively. It could also mean that the faculty should be less stringent when it comes to criteria in collaboration with industry.

\subsection{Student support}

Supporting students throughout their work-integrated learning experience is essential. The focus on project quality and the project outcome makes the student's situation vulnerable. The learning process itself might move to a secondary level. And although the real-life working environment provides added value in any way, it is mandatory to provide added value for the learning situation as well.

Our project and preliminary tool to define learning outcomes and an approach to reach it, prove to be promising. All stakeholders appreciate the added value it can deliver. Nevertheless, the daily working routines in the companies and the project focus could easily lead to neglecting the process and the follow-up.

Also, the pilot project revealed that the combination of two supervisors, an academic and an industrial supervisor might be beneficial for the student, it can also create confusion when it turns out that visions diverge during the project. The academic supervisor watches over the academic criteria for the project while the industrial supervisor mainly investigates the project outcome.

\subsection{Self-reflection}

For the students to reach a self-learning competence, the aspect of self-reflection is essential. The lightweight tool contributes to this self-reflection. At the same time, the lightweight process also holds the risk to result in meaningless reflections regarding tasks rather than competences. Therefore, it is essential to integrate self-reflection questions or assignments that surpass the superficial and encourage the student to reflect in a meaningful way regarding the proper competences.

\subsection{Enable the conversation}

The most important added value the integrated tool can provide is to make the conversation between the student and the external supervisor explicit. The tool facilitates the actual engagement between both parties. It defines the role of the supervisor for specifying a learning process for the student through feedback and defined actions. The student is forced into a process of self-reflection and self-evaluation regarding the project and the personal progress. The 10-month process provides enough opportunities for in-between feedback and mutual deliberation on actions to be taken to improve the learning process. 


\subsection{Capture the process}

Our preliminary evaluation of the work-integrated learning process in the context of design and development reveals that a continuous overview of the learning process, the criteria, the deliverables and the milestones is essential for the external supervisors to engage with the learning process and the student. Clear expectations embedded in a lean flow along a well-defined project are essential for the success of the cooperation. Work-integrated learning asks for a clear engagement of the external supervisor and this can only be achieved with lean supporting tools to engage them in the right conversation.

\subsection{Conclusion}

All together we believe that work-integrated learning could provide added value in an academic context. The close interaction between an academic supervisor, a student and an industrial supervisor creates a unique and strong setting in which the student can excel. The skills that can be developed in the industrial setting are very complementary to the academic learning outcomes. Perhaps, more important, the working situation leads to more self-confidence for the students when they must present themselves in the real world. They have better insights in their own capabilities and that would certainly be beneficial for the real-world matchmaking.

\section{ACKNOWLEDGEMENT}

The work-integrated learning project in the academic context of a masters' programme in product development was made possible through the European Social Fund (ESF). An 18-month grant was provided by ESF to run a pilot project in the faculty of design sciences and to translate the learnings to a broader setting within and outside the University of Antwerp.

\section{REFERENCES}

[1] Kolb, D., et al. (1984). Experiential learning: Experience as the source of learning and development. Englewood Cliffs. NJ: Prentice-Hall.

[2] Ash, S.L. \& Clayton, P. H. (2009). Teaching and learning through critical reflection: a tutorial for service-learning students. Accompanying Instructor Version. Raleigh, NC.

[3] Ash, S.L. \& Clayton, P.H. (2009). Generating, deepening, and documenting learning: The power of critical reflection for applied learning. Journal of Applied Learning in Higher Education, 1 (1). 